\title{
Building Capacity For Digital Development In The Arab World: The Role Of Education
}

\author{
Amer Al-Roubaie
}

\begin{abstract}
The digital economy is identified with the $4^{\text {th }}$ industrial revolution reflecting the importance of the digital technologies for development. In particular, the 4th industrial revolution holds prospect for developing countries to benefit from new opportunities brought by the new digital technologies spurring knowledge creation, innovation, skill intensification of the work-force and productivity enhancement. Economic development is a process of structural transformation that requires knowledge creation, knowledge sharing and knowledge acquisition. Digital technologies facilitate access to global markets allowing developing countries taking advantage of the information age to strengthen knowledge creation, innovation diffusion and information dissemination. Education plays critical role in building capacity for development in the digital economy. Participation in the digital economy requires new managerial and technical skills to stimulate technological learning and facilitate cooperation and collaboration. Education increases the country stock of capital essential for building capacity for innovation and supporting sustainable development. In other words, education drives knowledge creation, technological breakthrough and new product development. This paper focuses on the role that education plays in strengthening the fundamentals for digital economy. In most Arab countries, development is factor-driven -- dependent largely on natural resources and labor. This paper examines the contribution of education to development in the era of the $4^{\text {th }}$ industrial revolution.
\end{abstract}

Keywords: Digitization, Education, Knowledge, $4^{\text {th }}$ Industrial Revolution

\section{INTRODUCTION}

Recently, substantial amount of literature has been written about the $4^{\text {th }}$ Industrial Revolution. It postulates that the $21^{\text {st }}$ century will be driven by digital technologies which involve transformation of human activities into technologicallybased relations that will alter the way we live, conduct our business, think and make decisions. The $4^{\text {th }}$ Industrial Revolution is driven by automation, artificial intelligence, robotics, the internet of things and e-services aimed at increasing the role technology plays in production, consumption, management and communication. The effect of these technologies is expected to be disruptive causing structural unemployment and increasing demand for people with soft skills, critical thinking, and problem solving. In other words, the new technologies require different kind of skills to support the 'exponential rather than a linear pace.' Digitization increases the economy's capabilities to close the digital divide and speeds up the process of global integration. To this end, building ICT capacity is essential for strengthening the economy connectivity and participating in the $4^{\text {th }}$ Industrial Revolution.

Revised Manuscript Received on April 19, 2019.

Amer Al-Roubaie
Currently, almost 30 present of the world population are connected using social media services to communicate and gain access to knowledge and information produced outside their communities. Such external access facilitates technological learning, enhances people's experience and increases the country's readiness to compete in the global markets. The developing countries, in particular, can take advantage of the new opportunities offered by the digital revolution and acquire skills, knowledge and information for development. In this age of digital technologies, knowledge is a global good can be easily acquired through ICTs, technology transfer, and collaboration. Investments in technological learning and human capital become critical for enabling the country to catch-up and meet the challenges of the $21^{\text {st }}$ century. Digital technologies must be incorporated into the national stagey to ensure that digital services contribute to innovation and technological advancement. Improving the quality of education is a key policy lever for digital development.

This paper sheds light on the current state of digital development in the Arab world. It focuses on the need for building digital capacity to strengthen the region's ability responding to the challenges of the $21^{\text {st }}$ century and deepening integration into the digital economy. For several decades, economic development in the region has been financed by revenues from the production and export of energy resources, mainly oil and gas. Recent trends in global energy prices have increased economic and financial vulnerability subjecting the economies of energy producers to a high degree of instability. This paper focuses on Arab countries capabilities to enhance digitization and integrate into the new digital economy. Speeding up the process of integration will require a well- defined strategy aimed at building readiness capacity to support knowledge creation, human resources development and innovation. Greater cooperation and collaboration could play an important role in building regional readiness and increasing the prospect for rapid digitization.

\section{THE FOURTH INDUSTRIAL REVOLUTION}

The fourth industrial revolution is a new term coined by Klaus Schwab to describe the impact of digital technologies on the $21^{\text {st }}$ century societies. The new technologies, including artificial intelligence (AI), robotics, automation, nanotechnology, biotechnology, and the Internet Of Things (IOT), are to cause social and economic disruption that requires resilient, flexible and innovative economies. 
Technological change requires greater labor market flexibility and lifelong learning to empower readiness and help economies catching up with rest of the world. "The Fourth Industrial Revolution (4IR) is disrupting economies and societies by redefining the way we work, live and interact with each other. The 4IR offers the potential to leapfrog stages of development - but it also makes the pathway to development less certain notably for emerging economies betting on industrialization and the demographic dividend." [1] In particular, the labor market must ensure that the workforce is equipped with adequate skills and updated knowledge to response to market disruption. Universities, research centers and vocational schools are to play an important task in the new economy providing the necessary technical, managerial and digital skills needed for improving labor market flexibility.

The Fourth Industrial revolution is built on the 'knowledge systems' of the previous Industrial revolutions, in particular the digital capabilities of the Third Industrial Revolution. [2] Digitization increases human capabilities to collaborate and share knowledge and information across geographical boundaries so that to build capacity for development. Participation in the $4^{\text {th }}$ Industrial Revolution provides new opportunities for individuals, organizations and institutions to make use of digital technologies and promote development. However, the scope of the challenges facing countries differ across the boundaries which put many of the developing countries in a disadvantage position due to managerial, technical, financial and skill deficits.

Klaus Schwab points out that the Fourth Industrial Revolution is fundamentally different for being identified with a wide range of new technologies that are 'fusing the physical, digital and biological worlds, impacting all disciplines, economics and industries, and even challenging ideas about what it means to be human.' [2] The $4^{\text {th }}$ Industrial Revolution offers new prospects about the future using artificial intelligence, smart technologies and robotics technologies to solve problems. The need for greater global integration and capability building of institutions and decision making in developing countries has become more acute with rise of digital technologies. Developing countries should invest in and promoting digital services that facilitate digital development and participate in the digital economy. To meet the challenges of the digital age and close the digital divide, developing countries must learn from the experience of others via colocation and partnership to increase knowledge transfer and technology diffusion. As pointed out by the World Bank by 2020 the increased use of digital technologies will add $\$ 1.4$ trillion to the total global output. [3]

Enabling countries to participate in the digital economy not only requires restructuring the productive system and increasing labor market flexibility, but also building ICTs infrastructure to promote access to global markets. Arab countries can enhance readiness and improve capabilities through access to international trade, Foreign Direct Investment (FDI), Global Value Chains (GVCs), skills development, institutional reforms, and knowledge acquisition. Firms in Arab countries can participate in the international production networks by "specializing in specific stages of the production process, and exploiting their comparative advantage without the need to develop all of the capabilities encompassed by the whole production chain."[4]

Arab countries can benefit from participation in international production networks to increase the share of manufacturing production and improve global competitiveness. The Global Value Chains (GVCs) increase production linkages which encourage local enterprises to participate in market activities as suppliers of inputs to foreign firms or as producers of goods and services for the domestic market. Exposure to stronger competition and due to knowledge and information flows, involvement of local enterprises in GVCs will improve domestic market capabilities to participate in the digital economy.

Although it is difficult to speculate about the future impact of the new technologies on human conducts, however, the response to the challenges must be inclusive involving public and private institutions, universities, organizations and all agencies of civil society. Cooperative and collaborative relations increase the society's ability to function in a disruptive environment that requires immediate response to changes in technology. Creativity and critical thinking becomes essential for finding solutions to the rapidly changing business environment.

Recent advancement in artificial intelligence has increased the role of smart machines using large volume of data to accomplish specific tasks much faster with high degree of reliability. Artificial intelligence began to enter into all aspects of human activities providing services in the fields of banking, manufacturing, health care and retail business. Adaptation of artificial intelligence technologies could empower human capabilities to function in a more productive environment. This enhances the society's ability to create knowledge, diffuse innovation and diversify the economy. Today, computers are preforming many layers of processing units at high speed to help individuals and organizations understand how complex problems are solved.

Arab countries can take advantage of the new opportunities offered by digital technologies to restructure the economic system and increase manufacturing production. Inadequate manufacturing infrastructure has weakened the ability of these countries to promote innovation and develop new methods to strengthen the technological base and increase productivity. "It is no longer possible to rely solely on efficiency and cost cutting for economic success: innovation, flexibility and adaptation to change are becoming the key ingredients." [1]

Digital technologies are replacing traditional business with e-commerce, e-finance and e-services using the internet as a powerful tool not only to deepen integration into the global markets and acquire knowledge and skills, but also to enhance competiveness and increase collaboration. Governments must improve readiness by investing in ICT infrastructure to ensure that businesses are connected to the rest of the world. This provides incentive, especially for young entrepreneurs, to actively participate in e-business and compete with global players. Online services also 
encourage local businesses to participate in global value chains (GVCs) which facilitate technological learning and linkages creation. It is estimated that businesses adapting digital technologies are making $26 \%$ more profit than those not using these technologies. Responding to the challenges of the $4^{\text {th }}$ Industrial Revolution requires Arab countries formulating effective digital strategy to support their economies readiness and participate in the digital economy. Investments in digital technologies must be integrated into their national development strategy to foster productivity and participate in the $4^{\text {th }}$ Industrial Revolution.

\section{THE ARAB WORLD}

For several decades, economic development in the Arab world has been financed by revenues from production and export of energy resources, mainly oil and gas. Currently, these revenues account for a large percentage of GDP, government revenues and expenditures and foreign exchange earnings of most Arab countries making petroleum and petroleum products the main financial backing of development. Fuel production and exports represent about half of the total exports of the Arab world, whereas manufactured goods exports account for about $25 \%$ in total exports. However, the share of other sectors, including agriculture and industry, represents small percentage of GDP reflecting low sectoral productivity and high dependency on production and export of a limited number of commodities. Low economic diversification makes Arab countries vulnerable to changes in global markets impacting development process by creating uncertainty and reducing confidence in the economy. For many Arab countries, changes in macroeconomic variables, including income, are highly correlated with changes in global energy prices. This could have a negative impact on the country's balance of payments by discouraging investment in the tradable sectors. Yet, there are several challenges facing Arab countries in their attempts to diversify the economy, including low quality of education, inadequate business environment and lack of research and development. Deepening integration in the global markets can increase the ability of Arab countries to learn lessons from the experience of other countries and 'tailor those lessons to their own needs and circumstances." [5] Data published by the United Nations Conference on Trade and Development (UNCTAD) show that product concentration and diversification indices of exports and imports for Arab countries are relatively high compared to the rest of world regions. For example, diversification and concentration indices for GCC countries were 0.619 and 0.376 respectively in 2017. As for the Organization of Oil Exporting Countries (OPEC) the values of the indices were 0.642 and 0.468 respectively for the same year. Both measures reflect the high dependency of the Arab world on international trade. [6]

Most locals rely on government sector and other state enterprises for employment. The contribution of the private sector remains inadequate to generate strong linkages and create new employment opportunities, especially for young people. In the Arab world, female participation in the workforce averaged $23.4 \%$ in 2014 compared to $75 \%$ participation rate for male. In relation to the rest of the world average of $50 \%$ for female and $76.7 \%$ for male, the Arab region has registered the lowest participation rates among all world regions [7] In recent years, rapid increase in population and the rise in number of graduates, especially among young people, has been putting pressure on governments in the region to restructure the labor market and encourage private firms taking greater share of business activities. In most Arab countries, the government sector by far the biggest employer. In Saudi Arabia two-thirds of workers are employed by the government whereas in Jordon the government employs $55 \%$ of total workers making these ratios among the highest in the world. [8]

In the new digital economy, the role of the private sector is crucial for supporting knowledge creation, innovation diffusion and economic diversification. The Arab world is in "need of economic growth that is based on a vibrant and growing private sector if it is to attain durably higher levels of gainful employment: only the private sector can create a sufficient number of jobs in a sustainable manner." [5] The $4^{\text {th }}$ Industrial Revolution requires workforce capable of generating creative ideas and technical skills relevant to the dynamism brought by the digital technologies. Responding to the challenges of the $21^{\text {st }}$ century, the Arab world needs to rethink development and invest in people to increase the stock of human capital and promote innovation. Diversification of the economy is an important step for reducing the risk of high trade concentration and increasing global competitiveness.

The $4^{\text {th }}$ Industrial Revolution is transforming the productive system using advanced technologies to reshape the future of production. The Arab world must adapt these technologies to empower individuals, enterprises and institutions building capabilities that make use of the emerging technologies and advance economic productivity. In this regard, focusing on productive sectors that provide comparable advantage and facilitate linkages creation and innovation diffusion becomes essential for economic diversification. To this end, restructuring the productive system must involve not only investment in the right skills but also in creating inclusive business environment that encourages entrepreneurship and sustain growth. Lack of diversification has always contributed to growth volatility in the Arab world [9]

In recent decades, Global Value Chains (GVCs) have provided developing countries with the opportunity to participate in global trade and compete in the global markets. GVCs involve producing parts and intermediate products for multinational corporations by setting up new plants which increase the country capabilities to generate linkages and encourage diversification. Industrialization is critical for economic productivity which countries need to promote through the formulation of sound policies and the creation of appropriate business environment. GVCs could allow countries to obtain technology, skills and know- how for setting up businesses in the domestic market. "Diversifying the economy, developing the private sector, and creating opportunities for the youth will require 
increasing the innovation content of the non-oil sector and navigating through the Fourth Industrial Revolution." [5]

Connectivity to global markets provides local entrepreneurs the opportunity to participate in GVCs through contracting new businesses producing goods and services for multinational corporations. Arab countries can create capabilities to compete in the marketplace by producing goods and services in partnership with foreign firms. No longer have countries needed to set up full scale capabilities to produce goods and services, but rather to set up assembly operations. Local firms can acquire new capabilities by participating in the global value chains to foster innovation and diversify local output. Starts up of new businesses in the domestic market will have positive impact on employment, productivity and competitiveness. Khaleej Times Newspaper reports that 19 or $20 \%$ of Arab World's 100 most promising startups are in UAE. Jordan tops the Arab region with 27 startups which most likely will shape the Fourth Industrial Revolution. In Bahrain, startups account for $90 \%$ of enterprises. [10]

Arab governments can provide support for local firms to participate in GVCs by introducing measures to facilitate connectivity, encourage local firms to collaborate with foreign firms and impose conditions for use of local inputs. These requirements should be selective to ensure that the new operations increase technological linkages that will generate additional linkages for development. "GVCs can facilitate access to global markets and integration in the global economy for developing countries, which no longer have to develop entire industry to generate exports, but can focus on fewer tasks within industry value chains." [11] The export-led growth model, especially in resource-based economies, did very little to stimulate linkages creation and encourage investments in non-resource sectors. The transition from a resource-based to competitive knowledge economies is crucial for responding to the challenges hindering integration into the $4^{\text {th }}$ Industrial Revolution.

Despite of the task taken by smart machines, the human capital remains critical in the development of the digital economy. Across the Arab world connectivity remains low to take advantage of the global markets and gain access to knowledge, information, skills, technology and finance. The share of Arab trade in total world trade is relatively low to facilitate access to FDI, knowledge, information, skills and technology. Recent report by the IMF shows that FDI in oil producing countries has declined over the past few years. In addition, most FDI is concentrated in commodity sectors creating very few job opportunities for local workers. [12]

\section{THE DIGITAL ECONOMY}

The rise of digitization as a result of the advanced technologies including, artificial intelligence, the Internet of Things, cloud computing and robotics, has changed human understanding about the impact of technology on human societies. In the world of business, digital technologies are transforming economies around the world into technologically-based activities. People worldwide are electronically connected to discuss common interests and challenges that lead to expand opportunities and obtain new knowledge. "Digital technologies have dramatically expanded the information base, lowered information costs, and created information goods. This has facilitated searching, matching and sharing of information and contributed to greater organization and collaboration among economic agents - influencing how firms operate, people seeks opportunities, and citizens interact with their governments." [13]

Digital technologies are transforming societies and economies in profound ways allowing individuals and organizations to exchange information, buy and sell goods and services on line, increase networking and enhance interactions between citizens and their governments. However, digital inclusion is critical for a nation's success to participate in the digital economy, and therefore, digital services must be inclusive to include all citizens. For society to realize its potential and foster digital development, it is essential that equal access to technology, education, the internet and business opportunities are provided to all. In 2016 , it was estimated that $9 \%$ of jobs in the 21 OECD member countries were automatable; however, by 2030 for $60 \%$ of jobs, at least one-third of the duties will be automated. [13]

The digital economy is defined as" an economy which functions primarily by means of digital technology, especially electronic transactions made using the internet." [14] World Investment Report defines the digital economy as the "application of internet-based digital technologies to the production and trade of goods and services." [15] It is to play an important role in development by promoting innovation, encouraging entrepreneurship, enhancing competitiveness and sustaining economic growth. Digital services are to utilize the use of ICT for absorbing knowledge, diversifying productivity and supporting development. Digital technologies are inclusive linking individuals, organizations and institutions to each other creating one global community that shares information, exchanges ideas and establishes partnership. Connectivity, using the internet, perhaps is the most noticeable features of the digital economy, and therefore, building capacity for connectivity could have a substantial impact on digital development. The importance of the digital economy is attributed to several factors: 1) it is affecting the lives of growing number of people; 2) it is a growing part of people's economic lives; 3 ) it is pervasive in doing businessto business; 4) it is encompassing an ever greater part of the global economy; 5) it is increasing used by governments to interact with citizens and to deliver services. [15]

The $4^{\text {th }}$ industrial revolution is driven by digital technologies influencing the way that people communicate, do business and work. In the digital economy, people living across geographical areas are connected through electronic devices that empower their capabilities to formulate strategies and make decisions which impact the performance of business enterprises and market activities. Such connectivity facilitates cooperation and collaboration among and within nations to exchange information and strengthen capabilities for digital development. In developing countries, digitization could improve sectoral productivity 
and encourage diversification. Digital technologies offer low cost services which strengthen the fundamentals for building capacity for digital economy. Countries with inadequate productive resources need not to spend too much capital to produce knowledge in the early stages of development. They can benefit from the knowledge in the rest of the world by improving connectivity, transfer of technology, collaboration and cooperation with foreign institutions. Given the state of factor endowments in the Arab world, building capacity for digital economy will empower the region's ability to diversify productivity and deepen integration into the global economy. Participation in the $4^{\text {th }}$ Industrial Revolution could help Arab countries to surpass several stages in their development and catch up with rest of the industrialized world.

Digital technologies could provide inclusive educational services to increase people capabilities not only through participation in the market place, but also to reduce inequalities by providing equal opportunity to all seekers in spite of their geographical locations, gender, race and linguistic differences. In higher education, students can increase their learning capabilities using collaborative technologies outside the classroom. Transforming the educational system into digitally-based services will allow universities to acquire new knowledge and adopt new culture that encourage adaptation of the new technologies and make use of them to enhance the capability for innovation, creativity and creation of new knowledge. For countries with limited resources, digital education improves the utilization of resources by providing cheaper learning methods to increase the stock of human capital, encourage entrepreneurship and stimulate growth.

Until today, only those connected to the digital world are benefiting from the $4^{\text {th }}$ industrial Revolution. Technology is allowing access to new knowledge, new products and new techniques that increased capabilities and improved efficiency. The new technologies are expected to have longterm impact on the process of development helping countries to catch-up by passing several stages of their developments. Transaction costs are expected to fall which will help countries to achieve comparative advantage and gain greater access to global markets.

The new technologies could enhance capabilities across society sectors by improving digital services and creating new opportunities that facilitate innovation, creativity and productivity. Digital technologies will enable individuals and organizations to engage with public institutions for promoting partnership, increasing collaboration and joint venture. Governments need to adapt the $4^{\text {th }}$ Industrial Revolution by constructing strategies and formulating policies that stimulate business and strengthen the fundamentals for digital economy.

In the case of Arab countries, the public sector remains influential over market activities. The new economy underscores the need for greater participation by private enterprises to encourage competition and gain access to global markets. The role of the government could be very supportive to push for rapid integration into the digital economy by enhancing readiness and increasing capabilities. "The Arab world will need its private sector to address youth unemployment, the current skills gap for the Fourth
Industrial Revolution and the inclusion of women in the workforce." [10]

With the exception of a few countries, the digital divide in the Arab world remains a matter of concern reflecting the inability of many of these countries to join the $4^{\text {th }}$ Industrial Revolution and support local development. Connectivity through the internet varies across countries in the region largely due to weak infrastructure and inadequate funding needed for digital services. To speed up the process of development and facilitate global integration, governments in the region must consider the digital divide as a policy priority and provide internet access to individuals and industries across the nation. Urgently, they need to formulate digital development strategy aimed at addressing some of the challenges hindering digital development. Not only governments should contribute to digital development by building digital capacity, but also they should encourage local enterprises including SMEs to adopt digital technologies. "While digital technologies are no short cut to development, they can be an enabler and perhaps an accelerator by raising the quality of the complements." [13]

The new economy is driven by networks and greater interaction among firms within nations and across boundaries. Building digital capacity allows local firms to benefit from adoption of digital skills that are necessary for technological learning and productivity growth. In short, the advancement of a digital economy depends on three pillars: digital infrastructure, digital firms (the digital sector) and digital adoption in broader economy. [15] The digital economy requires some degree of flexibility due to changes in technology and the need for business firms to adapt quickly to changes in market demand.

Integration in the digital economy requires innovative and creative business environment that encourages partnership between local and foreign firms to establish joint business operations and facilitate knowledge absorption, technology transfer and information dissemination. Collaboration and cooperation with foreign firms creates demand for skills and technology which support entrepreneurs in developing, marketing and producing goods and services in a commercial manner. Local entrepreneurs should be involved from the outset in digital transformation. Empowering local innovators could improve technology development by allowing local firms recreate and diffuse new technologies to foster the production of goods and services by local entrepreneurs. [16]

Without technological, digital, scientific and talent readiness, the Arab world will face difficulties to meet the challenges of the coming age of digitization. Currently, the Arab world is going through unpredictable socio-political transformation with little attention is paid for building readiness capacity to join the digital economy. Most Arab countries are still heavily dependent on the rest of the world for supply of capital goods and raw materials for development. Manufacturing production has been hindered by inappropriate business environment, inadequate skills and lack of financing to encourage entrepreneurship and

Blue Eyes Intelligence Engineering

\& Sciences Publication

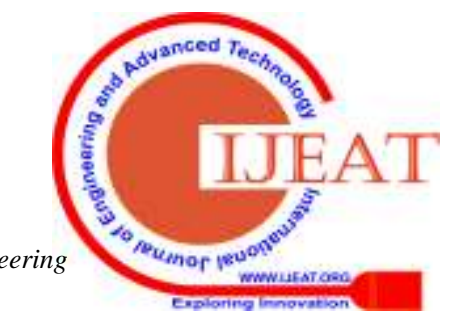


enhance economic diversification. Most economies are still producing traditional products with little knowledge contents to support innovation and foster change. Energy production and exports are still among the dominant industries in Arab countries with income earned from these industries account for a large percentage of the country's GDP.

\section{BUILDING CAPABILITIES THROUGH EDUCATION}

Education policy needs to be redefined to face the challenges related to changes in digital technologies and the need for greater flexibility to respond to market demand. It represents core components of the digital economy and therefore it should be integrated into the national digital strategy. The new technologies require communication skills, critical thinking and problem solving, creative thinking, leadership skills, technical skills, and collaboration/teamwork skills. In the digital economy, technology can substitute for shortages of qualified people to provide citizens in different locations with services that improve health, education, agricultural production and sustainable development.

The role of education must be designed to build indigenous capabilities that stimulate local linkages and broaden the economy's capacity to create indigenous knowledge, diffuse innovation and foster economic growth. Building capabilities for development require high quality educational system capable of training students in scientific application and critical thinking to generate new ideas and support innovation. Education increases the stock of human capital which is critical for building indigenous capabilities and diversifying productivity. Shortages of skills and talent hinder technological learning and weaken development efforts to benefit from opportunities offered by the new technologies driving the $4^{\text {th }}$ Industrial Revolution.

Local enterprises draw on domestic resources, including skilled labor, to build capabilities for productive capacity and bridge the digital divide. Initiatives by Arab countries must include measures to rethink the educational system to enable local entrepreneurs participate in the digital economy. Across the Arab world, schools are still using outdated curricula producing students unfit for employment in the digital economy. In this regard, the role of universities and research centers is critical for supplying technical, managerial, scientific and digital skills that are necessary for participating in the digital world. A recent survey by the Economist Intelligence Unit found that "onlinecollaboration tools, software that supports individually paced learning and learning-management systems are among the communications technologies most expected to improve academics over the next five years." (17)

Education represents the cornerstone of the new economy driven by digital technologies. The current system for education employed in many countries, including the Arab world, is not adequate enough to prepare the youth for the future labor market. Students are graduating with skills not necessarily sufficient to meet the rapidly changing labor market need for the new economy. "There is an increasing disconnect between the content-driven education model largely developed in the 19th century and today's rapidly evolving, skills-based world of work." [18] In other words, these models were based on theories that may not meet the current and future needs of the labor market. The new economy, driven by creativity, innovation and knowledge, require people with soft skills, technical skills, creative thinking, problem solving, team work, digital literacy and time management. Strengthening the fundamentals for digital economy entails flexible educational system capable of training students in technical and scientific subjects relevant to market demand. [19]

Across the Arab world, schools are underfunded and understaffed graduating students lacking to some of the basic scientific and technical knowledge needed to support integration into the digital economy. Large numbers of the school systems are not adequately equipped with well trained teachers, especially in digital technologies, to help students acquire adequate skills for integration into the 4th Industrial Revolution. Digital literacy, internet connectivity, life-long learning and computer-based applications are important components of the new model for education. Continuous training of teachers becomes necessary to enhance the school system delivery and meet the demand for new skills. Arab countries need to restructure the current educational system in line with current and future labor market needs. Integration of the Arab world into the digital economy requires more attention be paid to the quality of higher education in order to increase the stock of human capital and foster productivity. Output of higher education facilities innovation and create linkages that encourage investments from both local enterprises and foreign firms.

Universities can take advantage of the digital technologies and offer online degree programs, in particular for those who live in isolated regions. Arab countries could benefit from such technologies by cutting back on financing educational institutions where poor people and other disadvantaged minorities live. Distance learning could enhance productivity and increase the country's capabilities to create knowledge and promote innovation. Social networking technologies are helping to build connections with people both locally and globally. Farmers, women, minorities and various other groups can use the new technologies to gain access to information and knowledge needed for supporting local enterprises and driving down the cost of direct contact

Digital curricula needs to be integrated into the educational system to help students building up their digital skills and increase their readiness for the new technologies. Inclusive curricula must include not only academic courses, but also courses that focus on global languages, computing, internet access and digital library to allow students connected to services provided by virtual university. The availability of these internet-based products encourages students to communicate and exchange ideas aimed at enhancing capabilities and developing self-directed learning. As a consequence, digital skills will be needed to facilitate accesses and gain benefit from e-learning and other online educational services. 

which the socio-economic transformation is driven and the social well-being becomes possible. It helps increasing economic productivity, promoting labor market flexibility and strengthening the country competitiveness in the global markets. Education increases the capability of the country to adapt the technologies of the 4th Industrial Revolution and integrate the economy into the 21 st century digital society. Digital services stimulate innovation and create linkages that diversify economic productivity and sustain development. In most Arab countries economic diversification remains low to broaden productivity and stimulate economic growth. Integration into the 21 st century entails institutional reforms to enhance the country managerial, technical, innovative and human capital capabilities needed to speed up the process of global integration and participate in the new digital economy.

Universities need to establish new programs to help solve problems, encourage critical thinking and facilitate technological learning. Universities in the Arab world need to establish partnership agreements with foreign universities to facilitate knowledge transfer and gain expertise in research, teaching and learning and problem solving. Due to rapid changes in technology, universities need to offer short term courses with a vocational emphasis not only to increase labor market flexibility, but also to prepare students taking advantage of the new opportunities offered by the 4th Industrial Revolution. Higher education becomes essential to increase the stock of human capital as well as to enhance student capabilities conducting research, which is essential for knowledge creation and innovation diffusion.

Increase cooperation and collaboration among universities will require the establishment of networks and data base to allow students in various Arab countries share information and exchange ideas about common problems. Linking universities establishes virtual library system which benefits student, faculty and researchers to gain access to information and acquire references for conducting research and solving problems. With exception of few countries, universities in the Arab world are lacking to adequate physical facilities, teaching materials and library resources to support educational delivery, create incentives and improve the quality of education. Arab countries also need to establish fund for supporting scientific research that include all Arab countries and cover projects across the Arab world to engage students in conducting research and find solutions to common problems. Digital technologies are helping institutions within and across regions to increase communication and share knowledge and information for teaching and learning, research and collaboration. Joint programs and projects among universities, not only reduce costs and improve efficiency, but also bring people together to work closely on projects of the national interest of all countries.

\section{CONCLUSION}

This paper examines the contribution of digitization to economic convergence in the Arab world. Recent literature on the $4^{\text {th }}$ Industrial Revolution focuses on new disruptive technologies the impact of which could cause structural unemployment, widen income inequalities and increase
Education is critical for digital development, the pillar by

uncertainty about future decisions making. Creativity, innovation and knowledge are among key drivers of the digital economy reflecting the need for advancing the country's capabilities to increase linkages and diversify productivity. In the digital economy, economic growth is a product of creative thinking, problem solving and innovation which demand highly skilled workforce capable of designing new products and enhancing competitiveness in the global markets. Unlike the previous revolutions, technologies driving the $4^{\text {th }}$ Industrial Revolution are to have a major impact on individuals, businesses and governments placing new demand for increasing readiness and responding to the challenges of the $21^{\text {st }}$ century.

The Arab world needs to increase capabilities to gain access to global markets and participate in the digital economy. Policy initiatives must focus on diversifying productivity through investments in higher education, ICT infrastructure and e-services to enable the economy taking advantages of the new opportunities offered by the new technologies. Governments in the region must take the lead by introducing institutional reforms and creating sound business environment that encourages both local and foreign firms to participate in development.

The private sector should be given greater role to play in the digital economy and participate in market activities. SMEs contribute to global integration through investments in productive products and creative technologies which increase competitiveness in the global markets. The exportled development model, currently applied in most Arab countries is no longer applicable to meet the challenges of the $21^{\text {st }}$ century. Dependence on natural resources makes the economy vulnerable to changes in prices and demand for energy in the global markets. Under such circumstance, economic diversification enhances the economy capabilities to create linkages and sustain growth.

Education is a key driver in the digital economy providing the necessary skills needed not only to meet labor market demand, but also to increase flexibility of the economy. The ability of the economy to adapt to digital technologies and facilitate integration into the global markets will depend on human capabilities to develop new products and invent new methods that encourage entrepreneurship and enhance technological learning. Thus, education must be integrated into the national economic policy to support dynamism and reshape the economic social, political and cultural environments. Decision makers must think strategically about the disruptive consequences of the digital technologies and propose answers to solve them. Shaping the future must not only be inclusive involving all people, but also empowering them to play greater role in Fourth Industrial Revolution. It is morally incorrect not to increase current capabilities to ensure that the coming generations will enjoy sustainable future.

\section{REFERENCES}

1 World Economic Forum, The Global Competitiveness Report 2018. Geneva: World Economic Forum; 2018, P. 1,8 
2 Schwab, K. Shaping the Future of the Fourth Industrial Revolution. New York: World Economic Forum, 2018, https://www.weforum.org/about/the-fourth-industrialrevolution-by-klaus-schwab

3 World Bank, Annual Report 2018. Washington: World Bank; 2018, P. $\quad$ P. http://www.worldbank.org/en/about/annual-report P.

4 A. Amendolagine, A. Prespitero, R. Rabellotti, M. Sanfilippo, and A. Seric, FDI, Global Value Chains and Local Sourcing in Developing Countries, IMF Working Paper WP/17/284 Washington: IMF, 2017, P. 3, 30

5 World Bank Group, The Arab World Competitiveness Report 2018, Washington: The World Bank; 2018, P. 30, 10,15

6 United Nations Conference on Trade and Development (UNCTAD) UNCTADstat https://unctadstat.unctad.org/wds/TableViewer/tableView .aspx ?ReportId $=120$

7 United Nations, Survey of Economic and Social Developments in the Arab Region 2015-2016, P. 57 https://www.unescwa.org/publications/survey-economicsocial-development-arab-region-2015-2016

8 World Economic Forum: How to Create more Jobs in a Fast-Changing Middles East https://www.weforum.org/agenda/2019/04/create-jobsmiddle-east-fast-changing-business-landscape/

9 World Bank, Harnessing the Global Recovery (2014), P. 7

https://openknowledge.worldbank.org/bitstream/handle/1 0986/18819/9781464803956.pdf?sequence=1\&isAllowe $\mathrm{d}=\mathrm{y}$

10 (Khaleej Times Newspaper April 2, 2019)

11 United Nations, Global Value Chains and Development, 2013, P. 24

12 International Monetary Fund; Regional Economic Outlook: Middle East and North Africa 2018 https://www.imf.org/en/Publications/REO/MECA/Issues/ 2018/10/02/mreo1018

13 World Bank, World Development Report 2016, Digital Dividends; Washington: World Bank, 2016, P. 6, 8, 4, 17

14 Oxford

Dictionary, https://en.oxforddictionaries.com/definition/digital_econ omy

15 UNCTAD, World Investment Report 2017; Geneva, United Nations 2017, p. 156, 156, 193 https://unctad.org/en/PublicationsLibrary/wir2017_en.pdf

16 Al-Roubaie A, Almubarak, M. Localization of Knowledge in GCC Countries, Middle Eastern Journal of Entrepreneurship, Leadership and Sustainable Development, Vol 1, No1. 2015: 1 - 15

17 Economist Intelligence Unit, The Future of Higher Education: How Technology will Shape Learning, P. 8 http://graphics.eiu.com/upload/the $\% 20$ future $\% 20$ of $\% 20 \mathrm{u}$ niversities.pdf 2008

18 Deloitte - Preparing Tomorrow's Workforce for the Fourth Industrial Revolution https://www2.deloitte.com/content/dam/Deloitte/global/ Documents/About-Deloitte/gx-preparing-tomorrowworkforce-for-4IR.pdf

19 Al-Roubaie, A. Building Capacity for Knowledge Economies in the Arab World: The Role of Human Capital, International Journal of Engineering \& Technology, 7 (4.9) (2018) 55 - 62. Website: www.sciencepubco.com/index.php/IJET 